\title{
Modeling gene sequences over time in 2009 H IN I Influenza A Virus populations
}

\author{
Natalia Goñi, Alvaro Fajardo, Gonzalo Moratorio, Rodney Colina and \\ Juan Cristina*
}

Address: Laboratorio de Virología Molecular, Centro de Investigaciones Nucleares, Facultad de Ciencias, Igua 4225, 11400 Montevideo, Uruguay Email: Natalia Goñi - tati24@adinet.com.uy; Alvaro Fajardo - afajardo@cin.edu.uy; Gonzalo Moratorio - moratorio@pasteur.edu.uy; Rodney Colina - rcolina@cin.edu.uy; Juan Cristina* - cristina@cin.edu.uy

* Corresponding author

Published: 4 December 2009

Virology Journal 2009, 6:215 doi:10.1186/1743-422X-6-215

This article is available from: http://www.virologyj.com/content/6/I/215

(c) 2009 Goñi et al; licensee BioMed Central Ltd.

This is an Open Access article distributed under the terms of the Creative Commons Attribution License (http://creativecommons.org/licenses/by/2.0), which permits unrestricted use, distribution, and reproduction in any medium, provided the original work is properly cited.
Received: 28 September 2009

Accepted: 4 December 2009

\begin{abstract}
Background: A sudden emergence of Influenza A Virus (IAV) infections with a new pandemic HINI IAV is taking place since April of 2009. In order to gain insight into the mode of evolution of these new HINI strains, we performed a Bayesian coalescent Markov chain Monte Carlo (MCMC) analysis of full-length neuraminidase (NA) gene sequences of $62 \mathrm{HINI}$ IAV strains (isolated from March $30^{\text {th }}$ to by July $28^{\text {th }}, 2009$ ).

Results: The results of these studies revealed that the expansion population growth model was the best to fit the sequence data. A mean of evolutionary change of $7.84 \times 10^{-3}$ nucleotide substitutions per site per year $(\mathrm{s} / \mathrm{s} / \mathrm{y})$ was obtained for the NA gene. A significant contribution of first codon position to this mean rate was observed. Maximum clade credibility trees revealed a rapid diversification of NA genes in different genetic lineages, all of them containing Oseltamivirresistant viruses of very recent emergence. Mapping of naturally occurring amino acid substitutions in the NA protein from 2009 HINI IAV circulating in 62 different patients revealed that substitutions are distributed all around the surface of the molecule, leaving the hydrophobic core and the catalytic site essentially untouched.
\end{abstract}

Conclusion: High evolutionary rates and fast population growth have contributed to the initial transmission dynamics of 2009 HINI IAV. Naturally occurring substitutions are preferentially located at the protein surface and do not interfere with the NA active site. Antigenic regions relevant for vaccine development can differ from previous vaccine strains and vary among patients.

\section{Background}

Influenza A virus (IAV) is a member of the family Orthomyxoviridae and contains eight segments of a singlestranded RNA genome with negative polarity [1]. IAV causes 300,000-500,000 deaths worldwide each year, and in pandemic years, this number can increase to 1 million (in 1957-1958) or as high as 50 million, as was seen in
1918-1919 [2]. Unlike most pathogens where exposure leads to lasting immunity in the host, IAV presents a moving antigenic target [3], evading specific immunity triggered by previous infections. This process, called antigenic drift, is the result of the selective fixation of mutations in the gene encoding the hemagglutinin (HA) protein, the major target for the host immune response [4]. Variants 
that best escape the host immune response are thought to have a significant reproductive advantage [5].

Another process, called antigenic shift, is also considered a major force in the evolution of IAV [4,5]. Antigenic shift occurs when the virus acquires an HA of a different IAV subtype via reassortment of one or more gene segments and is thought to be the basis for the more devastating influenza pandemics that occurred several times in the last century [6]. New IAV pandemics may emerge through reassortation with strains from swine or avian reservoirs [7].

There have been three pandemics in the last hundred years: in 1918 (H1N1 subtype) [8], 1957 (H2N2 subtype) [9], and in 1968 (H3N2 subtype) [10]. During each of these pandemics, the new virus drove the previous pandemic subtype out of circulation [3]. In 1977, the H1N1 subtype reappeared, and has been co-circulating with H3N2 since then $[11,12]$.

IAV H3N2 viruses have been the predominant strains during the last 20 years, with the exception of the 1988-1989 and 2000-2001 seasons where H1N1 infections dominated [13].

A sudden emergence of IAV infections with new H1N1 strains of pandemic potential is taking place since April of 2009, starting in Mexico and spreading to several other countries around the world [14]. The World Health Organization (WHO) has raised the Influenza pandemic alert to the maximum level 6 [15].

Oseltamivir phosphate is a prodrug of oseltamivir carboxylate, a highly specific inhibitor of IAV neuraminidases. Oseltamivir carboxylate binds to highly conserved, essential amino acids in the catalytic site of neuraminidase (NA), preventing virus release from infected cells and subsequent virus spread [16]. An amino acid substitution at position $275(\mathrm{H} 275 \mathrm{Y})$ of the NA protein has been associated to resistance to Oseltamivir [17].

Initial testing of the 2009 pandemic H1N1 IAV strains found the viruses to be susceptible to neuraminidase inhibitors (oseltamivir and zanamivir).

Detailed studies on the mode of evolution of these new H1N1 IAV strains are extremely important for our understanding of the molecular mechanisms involved in the emergence, spread and resistance of new H1N1 IAV strains of pandemic potential. In order gain insight into these matters, we have performed a Bayesian coalescent Markov chain Monte Carlo analysis of full-length NA gene sequences of 62 emerging 2009 H1N1 IAV strains (isolated from March $30^{\text {th }}$ to July $28^{\text {th }}, 2009$ ). The results of these studies revealed high rate of evolutionary change of NA genes, fast expansion of the H1N1 IAV populations and emergence of anti-viral resistant viruses. Naturally occurring amino acid substitutions in the NA of H1N1 IAV strains circulating in 62 different patients preferentially located at the protein surface and do not interfere with the NA active site.

\section{Methods \\ Neuraminidase sequences}

Full-length NA sequences from the 2009 emerging H1N1 IAV strains, were obtained from The Influenza Virus Resource at the National Center for Biotechnological Information [18]. For strain names, dates of isolation and accession numbers see Table S1, Additional file 1.

\section{Sequence alignment}

NA sequences were aligned using the MUSCLE program [19].

\section{Evolutionary Model analysis}

Once aligned, the FindModel program [20] was used to identify the optimal evolutionary model that best fitted our sequence dataset. Akaike Information Criteria revealed that the General Time Reversible (GTR) model was the best fit to the data (Table S2, Additional file 2).

\section{Recombination Detection Tests}

To test whether a recombination event occurred on any of the sequences included in these studies, two different approaches implemented in the SimPlot program [21] were used: (1) a sliding window analysis of distances and (2) the bootscanning [22]. No recombinant strains were found in the datasets (not shown).

\section{Bayesian Coalescent Inference Studies}

The evolutionary rate and mode of evolution of the newly emerging 2009 H1N1 IAV strains were determined using a coalescent Bayesian Markov chain Monte Carlo (MCMC) approach as implemented in the BEAST package [23]. Sixty-two full-length NA gene sequences were included in these analyses. For names, accession numbers and date of isolation of strains included in these studies, see Table S1, Additional file 1,. Using the GTR model, 60 million steps of MCMC and dates introduced by day of isolation, different population dynamic models were tested (constant population size, exponential population growth, expansion population growth, logistic population growth and Bayesian Skyline). Statistical uncertainty in the data was reflected by the $95 \%$ highest probability density (HPD) values. Results were examined using the TRACER program from the BEAST package [24]. Convergence was assessed with ESS (Effective Sample Size) values, after a burning of 6 million steps. Maximum clade credibility trees were generated using Tree Annotator from 
the BEAST package and the FigTree v1.2.2 (available at: http://tree.bio.ed.ac.uk/) was used for the visualization of the annotated trees.

\section{Results}

Modelling gene sequences changes over time in NA gene of 2009 HINI emerging strains

In order to gain insight into the evolutionary rate and mode of evolution of 2009 H1N1 IAV strains, we used a Bayesian Markov Chain Montecarlo (MCMC) approach to analyze 62 full-length NA gene sequences from 2009 H1N1 IAV strains isolated from March $30^{\text {th }}$ to July $28^{\text {th }}$, 2009 (for strains names, accession numbers and dates of isolation, see Table S1, Additional file 1,).

Using the GTR model and 60 million steps of MCMC, different population dynamics models were tested (constant population size, exponential population growth, expansion population growth, logistic population growth and Bayesian skyline). Statistical uncertainty in the data was reflected by the $95 \%$ highest probability density (HDP) values. Convergence was assessed with Effective Sample Size (ESS) values, after a burning of 6 million steps. Comparison of the values obtained for marginal likelihoods as well as ESS of these models revealed that the Expansion Population Growth model was the best to fit the data.

The results shown in Table 1 are the outcome of the analysis for 60 million steps of the MCMC, using the GTR model, a relaxed clock [24] and the Expansion Population Growth model [25].

As can be seen in Table 1, our results suggest that the NA gene of the 2009 H1N1 emerging IAV strains evolved from ancestors that existed around August $17^{\text {th }}, 2008$. This is in agreement with previous results situating the most recent common ancestor (MRCA) for the NA gene of 2009 H1N1 IAV around August $8^{\text {th }}, 2008$ [26].

When the GTR model is used, a mean of $7.84 \times 10^{-3}$ nucleotide substitutions per site per year $(\mathrm{s} / \mathrm{s} / \mathrm{y})$ was obtained for the NA gene (Table 1). This rate is roughly comparable to previous estimations of IAV NA evolutionary rates (3.6 $\times 10^{-3} \mathrm{~s} / \mathrm{s} / \mathrm{y}$ ) [26]. Interestingly, a significant contribution of the first codon position to the evolutionary rate was also found (Table 1). Moreover, an important expansion growth rate was observed (see Table 1).

\section{Phylogenetic tree analysis of NA genes from 2009 HIN I IAV strains}

To study the phylogenetic relations among the NA genes from the $62 \mathrm{H} 1 \mathrm{~N} 1$ IAV strains enrolled in these studies, maximum clade credibility trees were generated using software from the BEAST package [23]. The results of these studies are shown in Figure 1.

As it can be seen in the figure, different genetic subbranches can be observed. Interestingly, Oseltamivirresistant viruses can be observed in all main genetic subbranches. These viruses are situated on the tip of the trees suggesting a recent emergence from the 2009 H1N1 IAV populations (see Figure 1). This is in agreement with the initial studies revealing that 2009 H1N1 IAV strains were susceptible to Oseltamivir and the recent selection of resistant viruses from these viral populations [17].

\section{Mapping of positive-selected and co-evolving sites in a 3D NA protein model}

An homology-based 3D structure model of the NA protein of 2009 H1N1 IAV strains have been very recently obtained [27] (available at http://mendel.bii.astar.edu.sg/SEQUENCES/H1N1/). In order to observe if the amino acids substitutions naturally occurring in the NA genes of the $62 \mathrm{H} 1 \mathrm{~N} 1 \mathrm{IAV}$ studied were associated to previously identified antigenic regions or the active site of the NA protein (being the latter the binding cavity of Oseltamivir and other NA inhibitors drugs), we mapped all substitutions found in NA proteins of all IAV enrolled in these studies in a temporal order, according to the date of isolation of each strain. The results of these studies are shown in Figure 2.

Table I: Bayesian coalescent inference of full-length NA sequences from 2009 HINI Influenza A virus strains.

\begin{tabular}{llllr}
\hline Group & Parameter & Value $^{\mathbf{a}}$ & HPD $^{\mathbf{b}}$ & ESS $^{\mathbf{c}}$ \\
\hline \multirow{2}{*}{62 NA sequences } & Log likelihood & -2601.35 & -2616.89 to -2586.07 & 1401.12 \\
& Mean Rated & $7.84 \times 10^{-3}$ & $7.59 \times 10^{-3}$ to $1.43 \times 10^{-2}$ & 26.75 \\
& Codon Ie & 0.97 & 0.67 to 0.95 & 40307.19 \\
& Codon 2 & 0.51 & 0.25 to 0.79 & 26291.08 \\
& Codon 3 & 1.51 & 1.17 to 1.86 & 206.45 \\
& Expansion Growth Ratef & 66.43 & 0.38 to 503.70 & 163.42 \\
& Root age (days) & 324.99 & 130.84 to 644.01 & September $27^{\text {th }}, 2007$ to March 9th, 2009.
\end{tabular}

aln all cases, the mean values are shown. b HPD, high probability density values. c ESS, effective sample size. d Mean rate was calculated in

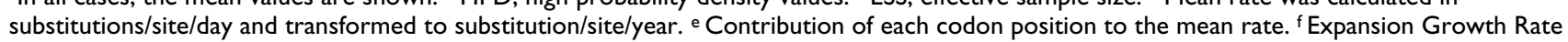
was calculated in number of new infections/individual/day and transformed to number of new infections/individual/year. 8 MRCA, day of the Most Common Recent Ancestor. 


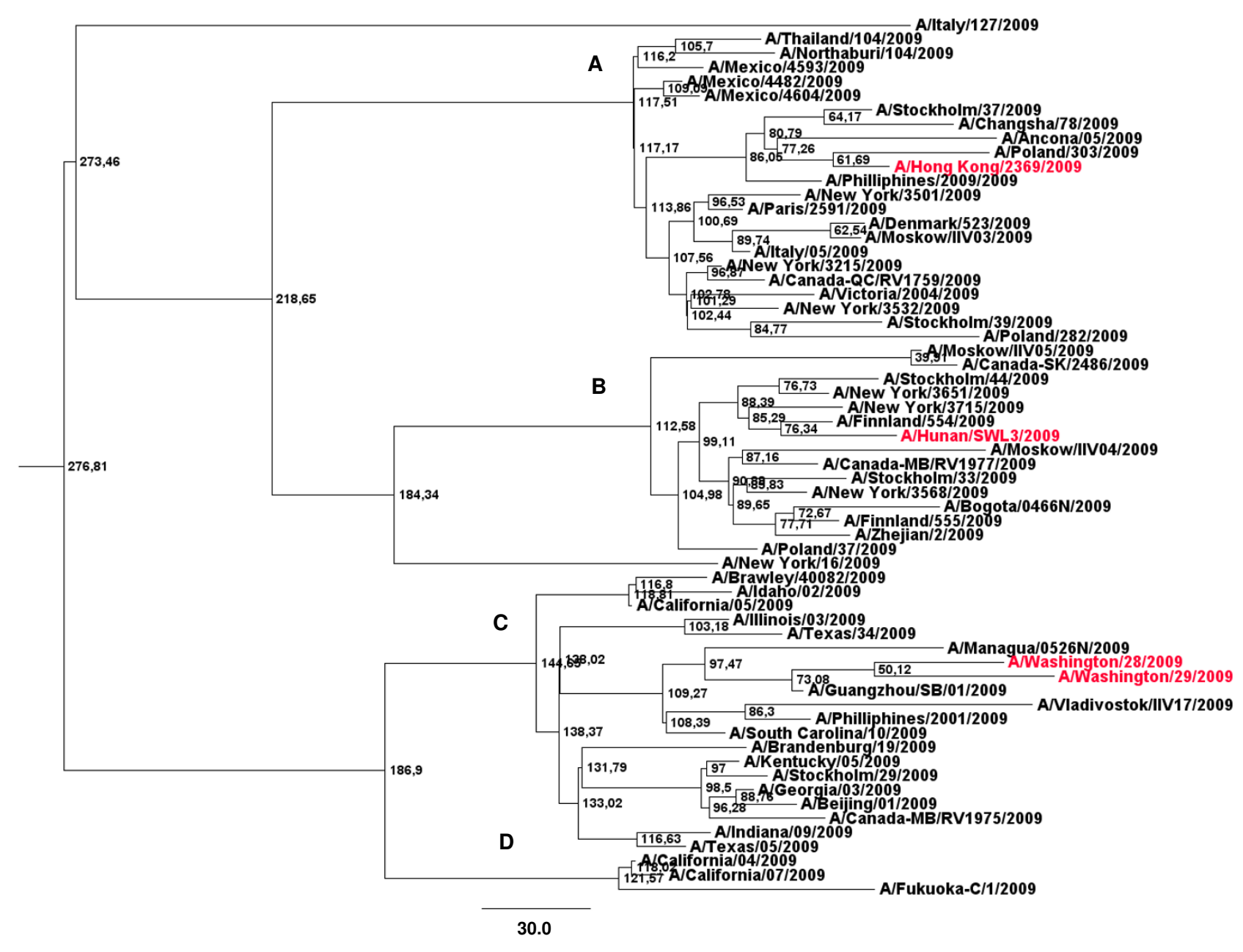

Figure I

Bayesian MCMC phylogenetic tree analysis of 62 NA genes from 2009 H IN I IAV strains. A maximum credibility clade obtained using the GTR model, the expansion population growth model and a relaxed clock (uncorrelated exponential) is shown. Strains in the tree are shown by name. Main genetic sub-branches are indicated by capital letters (A through D). Node ages are shown in days at the nodes of the tree. The tree is rooted to theirMRCA. Bar at the bottom of the tree show time in days. Strains carrying the $\mathrm{H} 275 \mathrm{Y}$, that confers resistance to Oseltamivir, are shown in red.

As it can be seen in the figure, no substitution was found to be related to the active site of the NA protein (see Figure 2). Importantly, none of the substitutions found in our dataset appears sufficiently close to affect the drug binding pocket (see Figure 2).

\section{Discussion}

The antigenic variability of IAV is the basis for the recurring epidemics each year [28]. IAV presents a moving antigenic target, evading immunity triggered by previous infections. For these reasons, efforts to characterize epidemic variants [29] are deemed important for improving influenza vaccine formulation, since the closer the vaccine strain is to the dominant variant, the more effective the vaccine [30].

A sudden emergence of new H1N1 IAV of swine origin is taking place since April of 2009 [15]. This pandemic started in Mexico and it is currently spreading to all regions of the world [14]. On June $11^{\text {th }}$, the WHO officially raised the phase of pandemic alert to level 6 . As of July $19^{\text {th }}, 137,232$ cases of the 2009 H1N1 IAV emerging strains have been officially confirmed in 142 countries [31]. 
A

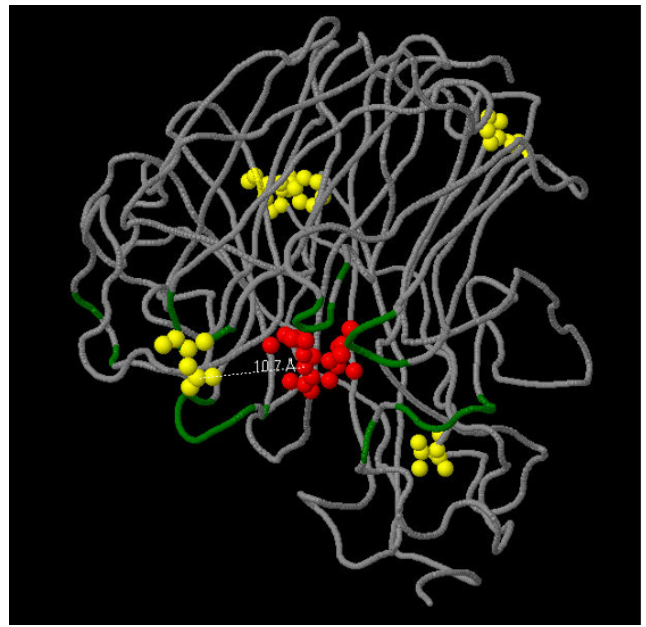

C

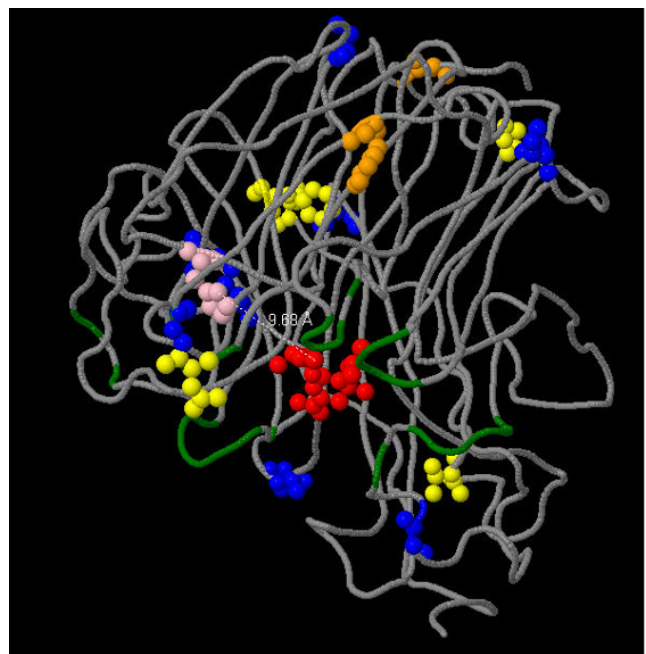

B

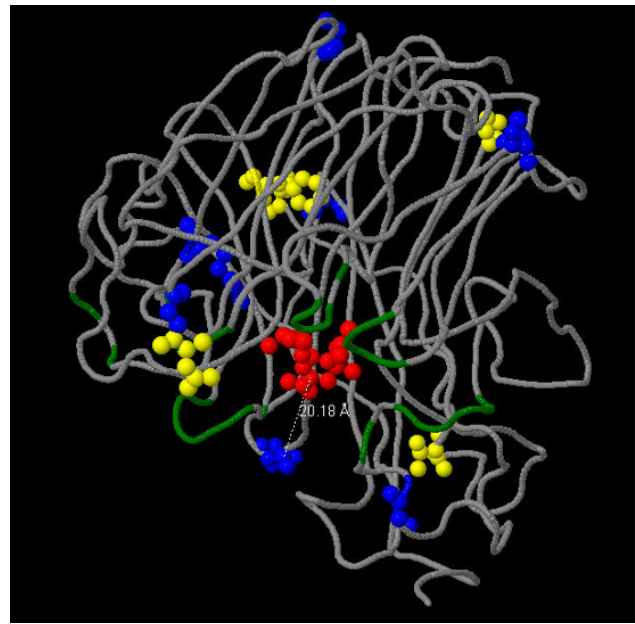

D

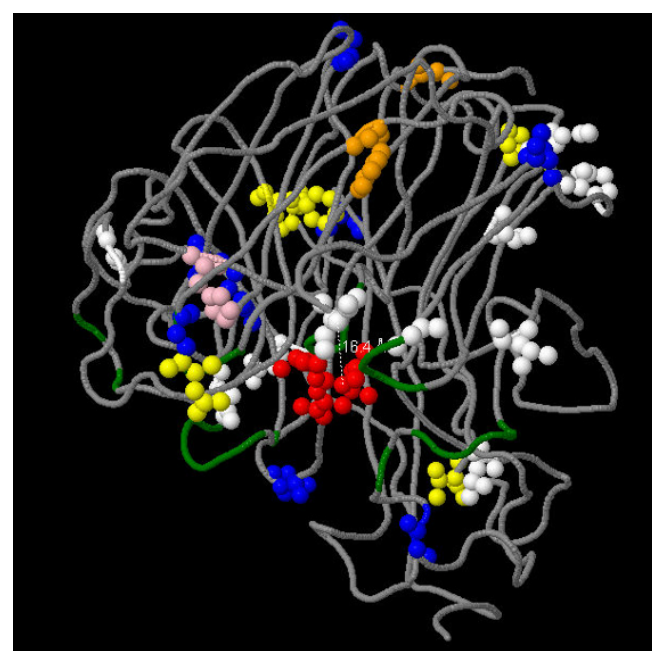

Figure 2

Mapping of naturally occurring amino acid substitutions in a NA protein 3D structure. The 3D structure model of the NA protein from 2009 HINI IAV shown in the figure was obtained by Mauer-Stroh et al. [27] (Bioinformatic Institute, A*STAR's Biomedical Sciences Institutes, Singapore). Oseltamivir atoms are shown in red. Antibodies binding sites are shown in green. Position 275, where substitution $\mathrm{H} 275$ Y confers resistance to Oseltamivir, is shown in pink. The substitutions found among strains isolated during 30,60, 90 (where viruses with $\mathrm{H} 275 \mathrm{Y}$ substitution also arise) and II 9 days (from March 30th, 2009) are shown in yellow, blue, orange and white in A through D, respectively. Dotted white lines show distances in $\AA$.

Different approaches have been extremely useful in increasing our understanding of the spatial-temporal transmission dynamics of influenza. They have also provided assistance in evaluating the potential severity of IAV pandemics, where severity was defined by the value of the Basic Reproduction Number $\left(R_{0}\right)$ [32].

The $R_{0}$ for novel influenza A (H1N1) has recently been estimated to be between 1.4 and 1.6 [33], revealing an important expansion of this IAV population. Fortunately, this value is below values of $R_{0}$ estimated for the 19181919 pandemic strain (mean $R_{0} \sim 2$, range 1.4 to 2.8) [32].
These results are in agreement with the results found in this work using a Bayesian coalescent MCMC approach (see Table 1). A high expansion growth rate (66.43 new infections/individual/year) was achieved, particularly considering the short period of time studied (March $30^{\text {th }}$ to July $\left.28^{\text {th }}, 2009\right)$. These results suggest that the pandemic caused by the 2009 H1N1 IAV will continue its expansion phase at a significant rate.

We estimated that the NA of the 2009 H1N1 IAV evolved from ancestors that existed around August 17th, 2008 (Table 1). Interestingly, this date is in agreement with first 
estimations of the MRCA for that gene of these pandemic strains (August $8^{\text {th }}, 2008$ ) [26]. This result suggests that the NA gene segment of these viruses were presumably circulating in the swine reservoir before emerging into the human population, in agreement with recent results [34].

The first estimation of evolutionary rate for the NA gene of the $2009 \mathrm{H} 1 \mathrm{~N} 1 \mathrm{IAV}$ strains established a rate of $3.65 \times$ $10^{-3}$ [26]. In this study, a mean evolutionary rate of $7.84 \times$ $10^{-3} \mathrm{~s} / \mathrm{s} / \mathrm{y}$ was obtained (see Table 1). Although not entirely dissimilar rates are found, the possible differences among the two estimations may be due to the fact that the first estimations were carried out at the beginning of the pandemic outbreak, where only 30 NA sequences isolated over a shorter time span (from March to May) were available [26]. In this work, 62 full-length NA sequences, isolated from March to the end of July, were employed (see Table S1, Additional file 1). Importantly, a contribution of first codon position of 0.97 (from a total of 3.0) to the mean evolutionary rate was found (Table 1 ). This speaks of a comparatively higher contribution of non-synonymous substitutions to the mean substitution rate. This result is in agreement with previous reports showing a comparatively higher non-synonymous to synonymous $(d n / d s)$ substitution rate ratio in the 2009 H1N1 IAV strains [26]. Moreover, a contribution of first codon position to main evolutionary rate like the one found in this study is significantly higher than the ones previously found in other RNA viruses, like Hepatitis A virus (0.33, VP1 gene) [35] and Noroviruses (0.55, VP1 gene) [36].

Maximum clade credibility trees revealed a rapid diversification of NA genes in at least four main phylogenetic lineages (Figure 1). Nevertheless, due to the fact that the degree of genetic variation among all strains included in these analysis is roughly low (with a maximum degree of variation of $0.64 \%$ ), more studies will be needed to confirm these findings. Interestingly, Oseltamivir resistance was found only in the more recent samples and two of them, the A/Washington/28/2009 and the A/Washington/29/2009, appear to be phylogenetically and geographically linked (Figure 1). This finding also suggests that anti-viral resistant viruses can emerge in any genetic lineage, as a result of selection of mutant viruses from the viral population. Oseltamivir-resistant viruses are situated on the tips of the tree. This reveals a recent emergence from previously susceptible viruses (Figure 1). This result is in agreement with initial studies showing the susceptibility of the H1N1 IAV emerging strains to this drug and its widespread use to combat the spread of these viruses all around the world [17].

Mapping of substitutions found in the 62 NA proteins during the four month period covered by this study revealed that substitutions are distributed all around the surface of the molecule, leaving the hydrophobic core and the catalytic site essentially untouched (see Fig. 2). Nevertheless, strains carrying the $\mathrm{H} 275 \mathrm{Y}$ substitution were also observed in these studies (see Figs 1 and 2). Very recent studies on the structure of the NA of mutant IAV strains carrying this substitution, revealed that the bulkier Tyr residue alters the orientation of the key Glu 277 residue [37]. On binding Oseltamivir, the conformation of the Glu 277 side chain of the wild type enzyme is altered such that it exposes a hydrophobic site with which the pentyloxy group of Oseltamivir interacts [37]. In the mutant enzyme, the bulkier Tyr residue at position 275 displaces the carboxyl group of Glu 277 into the binding site, such that it disrupts the hydrophobic pocket and causes a change in conformation of the pentyloxy substituent of Oseltamivir, with consequent reduction in affinity of binding of some 300-fold or greater [38].

Interestingly, this is not the case of Zanamivir, since the H275Y substitution causes only a small shift in the position of Glu 277, without disrupting the H-bonds between Glu 277 and the glycerol moiety of the drug [38]. This suggests that other NA inhibitors, like Zanamivir or Peramivir should still be effective against this H1N1 IAV strains. Importantly, substitutions observed in the 62 patients enrolled in this study suggest that changes at possible antigenic sites at NA protein surface may indeed occur (see Figure 2). For that reason, vaccines to previous strains or acquired immunity from previous IAV infections are expected to be less effective. More detailed studies on the 2009 H1N1 IAV evolution are extremely needed in order to select appropriate IAV vaccine strains.

\section{Conclusion}

A coalescent Bayesian Markov Chain Montecarlo (MCMC) approach was used to analyze 62 full-length NA gene sequences from $2009 \mathrm{H} 1 \mathrm{~N} 1$ IAV strains, isolated from March $30^{\text {th }}$ to July $28^{\text {th }}, 2009$. When the Expansion Population Growth model was employed a high rate of evolutionary change of $7.84 \times 10^{-3} \mathrm{~s} / \mathrm{s} / \mathrm{y}$ was obtained for the NA gene. Importantly, a significant contribution of the first codon position to the mean evolutionary rate was also found. Moreover, an important expansion growth rate of 66.43 new infections/individual/year was also observed. Taking these results together, high evolutionary rates and fast population growth have contributed to the initial transmission dynamics of 2009 H1N1 IAV. Naturally occurring substitutions are preferentially located at the protein surface and do not interfere with the NA active site. Antigenic regions relevant for vaccine development can differ from previous vaccine strains and vary among patients.

\section{Competing interests}

The authors declare that they have no competing interests. 


\section{Authors' contributions}

NG and JC conceived the study. AF, GM and JC designed and performed the Bayesian coalescent studies and phylogenetic analysis. NG, AF, GM and RC contributed to the discussion and interpretation of the results. JC wrote the paper. All authors read and approved the final manuscript.

\section{Additional material}

\section{Additional file 1}

Origins of the NA sequences from 2009 H1N1 IAV strains. A table describing the names, date of isolation and accession numbers of all IAV strains included in this study.

Click here for file

[http://www.biomedcentral.com/content/supplementary/1743422X-6-215-S1.DOC]

\section{Additional file 2}

FindModel results for NA genes of 2009 H1N1 IAV strains. A table describing the results found for different evolutionary models tested in this study.

Click here for file

[http://www.biomedcentral.com/content/supplementary/1743422X-6-215-S2.DOC]

\section{Acknowledgements}

We acknowledge support by International Atomic Energy Agency, through Research Contract No. 15792 and Comisión Sectorial de Investigación Científica (CSIC), Universidad de la República, Uruguay, through I+D Project "Variabilidad Genética y Evolución Viral de Virus Influenza A en Uruguay". NG and JC acknowledge support by Agencia Nacional de Investigación e Innovación (ANII) and PEDECIBA, Uruguay.

We thank anonymous reviewers for important advice in improvement of this work.

\section{References}

I. Neumann G, Brownlee GG, Fodor E, Kawaoka Y: Orthomyxovirus replication, transcription, and polyadelynation. Curr Top Microbiol Immunol 2004, 283: I 2 I- I 43.

2. Nguyen-Van-Tam JS, Hampson AW: The epidemiology and clinical impact of pandemic influenza. Vaccine 2003, 21 : I762-I768.

3. Wolf YI, Viboud C, Holmes EC, Koonin EV, Lipman DJ: Long intervals of stasis punctuated by bursts of positive selection in the seasonal evolution of influenza A virus. Biology Direct 2006, I:34.

4. Hillerman MR: Realities and enigmas of human viral influenza: pathogenesis, epidemiology and control. Vaccine 2002, 20:3068-3087

5. De Jong JC, Rimmelzwaan GF, Fouchier RA, Osterhaus AD: Influenza virus: a master of metamorphosis. J Infect 2000 , 40:218-228.

6. Ferguson NM, Galvani AP, Bush RM: Ecological and immunological determinants of influenza evolution. Nature 2003 422:428-433.

7. Kilboune ED, Smith C, Brett I, Pokorny BA, Johansson B, Cox N: The total influenza vaccine failure of $\mid 947$ revisited: major intrasubtypic antigenic change can explain failure of vaccine in a post-World War II epidemic. Proc Natl Acad Sci USA 2002, 99: $10748-10752$.

8. Smith GID, Bahl J, Vijaykrishna D, Zhang J, Poon LLM, Chen H, Webster RG, Malik JS, Guan Y: Dating the emergence of pandemic influenza viruses. Proc Natl Acad Sci USA 2009, I 06: I I 709-I I 72.
9. Scholtissek C, Rohde W, Von Hoyningen V, Rott R: On the origin of the human influenza virus subtype $\mathrm{H}_{2} \mathrm{~N} 2$ and H3N2. Virology 1978, 87:13-20.

10. Kawaoka Y, Krauss S, Webster RG: Avian-to-human transmission of the PBI gene of influenza $A$ viruses in the 1957 and 1968 pandemics. J Virol 1989, 63:4603-4608.

II. Scholtissek C, von Hoyningen V, Rott R: Genetic relatedness between the new 1977 epidemic strains (HINI) of influenza and human influenza strains isolated between 1947 to 1986 as determined by oligonucleotide mapping and sequencing studies. J Gen Virol 1978, 70:299-313.

12. Cox NJ, Black RA, Kendal AP: Pathways of evolution of influenza A (HINI) viruses from 1977 to 1986 as determined by oligonucleotide mapping and sequencing studies. J Gen Virol 1978 , 70:299-313.

13. Lin YP, Gregory V, Bennett M, Hay A: Recent changes among human influenza viruses. Virus Res 2004, 103:47-52

14. Centers for Disease Control and Prevention: Update: infections with a swine-origin influenza A (HINI) virus - United States and other countries, April 28, 2009. MMWR Morb Mortal Wkly Rep 2009, 58:431-433.

15. Zaracostas J: World Health Organization declares A (HINI) influenza pandemic. BMJ 2009, 338:b2425.

16. Aoki FY, Boivin G, Roberts N: Influenza virus susceptibility and resistance to oseltamivir. Antivir Ther 2007, I 2:603-6I6.

17. Centers for Disease Control and Prevention: Oseltamivir-resistant 2009 pandemic influenza $A$ (HINI) virusinfection in two summer campers receiving prophylaxis--North Carolina, 2009. MMWR Morb Mortal Wkly Rep 2009, 58:969-972.

18. Bao Y, Bolotov D, Dernovoy B, Kiryutin L, Zaslavsky L, Tatusova T, Ostell J, Lipman D: The Influenza Virus Resource at the National Center for Biotechnology Information. J Virol 2008 , 82:596-60I

19. Edgar RC: MUSCLE: a multiple sequence alignment method with reduced time and space complexity. BMC Bioinformatics 2004, 5: I13.

20. Posada D, Crandall KA: Selecting the best-fit model of nucleotide substitution. Syst Biol 200I, 50:580-60I.

21. Lole KS, Bollinger RC, Parnjape RS, Gadkari D, Kulkarni SS: Ful length human immunodeficiency virus type I genomes from subtype C-infected seroconverters in India, with evidence of intersubtype recombination. J Virol 1999, 73:152-160.

22. Salminen MO, Carr JK, Burke DS, McCutchan FE: Identification of break-points in intergenotypic recombinants of HIV type I by bootscanning. AIDS Res Hum Retroviruses 1995, I I: 1423-1425.

23. Drummond AJ, Rambaut A: BEAST: Bayesian evolutionary analysis by sampling trees. BMC Evol Biol 2007, 7:214.

24. Drummond AJ, Ho SYW, Phillips MJ, Rambaut A: Relaxed phylogenetics and dating with confidence. PLoS Biol 2006, 4:88.

25. Drummond AJ, Rambaut A, Shapiro B, Pybus OG: Bayesian coalescent inference of past population dynamics from molecular sequences. Mol Biol Evol 2005, 22: I I85-I I92.

26. Smith GJ, Vijaykrishna D, Bahl J, Lycett SJ, Worobey M, Pybus OG, Ma SK, Cheung CL, Raghwani J, Bhatt S, Peiris JS, Guan Y, Rambaut A: Origins and evolutionary genomics of the 2009 swine-origin HIN I influenza A epidemic. Nature 2009, 459: I I22-I I 25.

27. Maurer-Stroh S, Ma J, Tze Chuen Lee R, Sirota FL, Eisenhaver F: Mapping the sequence mutations of the 2009 HINI influenza A virus neuraminidase relative to drug and antibody binding sites. Biology Direct 2009, 4: I8.

28. De Jong JC, Rimmelzwaan GF, Fouchier RA, Osterhaus AD: Influenza virus: a master of metamorphosis. J Infect 2000, 40:218-228

29. Wolf YI, Viboud C, Holmes EC, Koonin EV, Lipman Dl: Long intervals of stasis punctuated by bursts of positive selection in the seasonal evolution of influenza A virus. Biology Direct 2006, I:34.

30. Nelson MI, Viboud C, Simonsen L, Bennett RT, Grieserner SB, St George K, Taylor J, Spiro DJ, Sengamalay NA, Ghedin E, Taubenberger JK, Holmes EC: Multiple reassortment events in the evolutionary history of HINI Influenza A Virus since 1918. PLoS Pathog 2008, 4:el0000I2.

31. Balcan D, Hu H, Goncalves B, Bajardi P, Poletto C, Ramasco J], Paolotti D, Perra N, Tizzoni M, Broeck W Van den, Colizza V, Vestignani $A$ : Seasonal transmission potential and activity peaks of the new influenza A (HINI): a Monte Carlo likelihood analysis based on human morbility. BMC Med 2009, 7:e45. 
32. Coburn BJ, Wangner BG, Blower S: Modeling influenza epidemics and pandemics: insights into the future of swine flu (HINI). BMC Med 2009, 7:e30.

33. Fraser C, Donnelly CA, Cauchmez S, Hanage WP, Van Kerkhove MD, Hollingsworth TD, Griffin J, Baggaley RF, Jenkins HE, Lyons EJ, Jombart T, Hinsley WR, Grassly NC, Balloux F, Ghani AC, Ferguson NM, Rambaut A, Pybus OG, Lopez-Gatell H, Alpuche-Aranda CM, Chapela IB, Zavala EP, Guevara DM, Checchi F, Garcia E, Hugonnet S, Roth C, WHO Rapid Pandemic Assessment Collaboration: Pandemic potential of a strain of Influenza A (HINI): early findings. Science 2009, 324:|557-|56|.

34. Garten RJ, Davis CT, Russell CA, Shu B, Lindstrom S, Balish A, Sessions WM, Xu X, Skepner E, Deyde V, Okomo-Adhiambo M, Gubareva L, Barnes J, Smith CB, Emerly SL, Hillman MJ, Rivailler P, Smagala J, de Graaf M, Burke DF, Fouchier RA, Pappas C, AlpucheAranda CM, Lopez-Gattel H, Olivera H, Lopez I, Myers CA, Faix D, Blair PJ, Yu C, Keene KM, Dotson PD Jr, Boxrud D, Sambol AR, Abid $\mathrm{SH}$, St George K, Bannerman T, Moore AL, Stringer DJ, Blevins P, Demmler-Harrison G], Ginsberg M, Kriner P, Waterman S, Smole S, Guevara HF, Belongia EA, Clark PA, Beatrice ST, Donis R, Katz J, Finelli L, Bridges CB, Shaw M, Jernigan DB, Uyeki TM, Smith DJ, Klimov Al, Cox NJ: Antigenic and genetic characteristics of swine-origin 2009 A (HINI) influenza viruses circulating in humans. Science 2009, 325:197-20I.

35. Moratorio G, Costa-Mattioli M, Piovani R, Romero H, Musto H, Cristina J: Bayesian coalescent inference of hepatitis $A$ virus populations: evolutionary rates and patterns. J Gen Virol 2007, 88:3039-3042.

36. Victoria M, Miagostovich MP, Ferreira MS, Vieira CB, Fioretti JM, Leite $J P$, Colina R, Cristina J: Bayesian coalescent inference reveals high evolutionary rates and expansion of Norovirus populations. Infect Genet Evol 9:927-932.

37. Collins PJ, Haire LF, Lin YP, Liu J, Russell RJ, Walker PA, Skehel JJ, Martin SR, Hay AJ, Gamblin SJ: Crystal structures of oseltamivirresistant influenza virus neuraminidase mutants. Nature 2008 , 453: $|258-| 26 \mid$.

38. Collins PJ, Haire LF, Lin YP, Liu J, Russell RJ, Walker PA, Martin SR Daniels RS, Gregory V, Skehel Jj, Gamblin SJ, Hay AJ: Structural basis for oseltamivir resistance of influenza viruses. Vaccine 2009, 27:6317-6323.
Publish with Bio Med Central and every scientist can read your work free of charge

"BioMed Central will be the most significant development for disseminating the results of biomedical research in our lifetime. "

Sir Paul Nurse, Cancer Research UK

Your research papers will be:

- available free of charge to the entire biomedical community

- peer reviewed and published immediately upon acceptance

- cited in PubMed and archived on PubMed Central

- yours - you keep the copyright
BioMedcentral 